\title{
Esquadrão Graphics: em repórter por um dia
}

\author{
Luiz Eduardo Rodrigues da Silva ${ }^{1,3}$, Felipe Gomes Rufino Moura Paiva ${ }^{1,3}$, \\ Antônia Hareta Alves Forte ${ }^{1}$, Samuel Pinheiro Barguil ${ }^{1}$, Juscileide Braga de \\ Castro $^{2,3}$, José Aires de Castro Filho ${ }^{3}$.
}

\footnotetext{
${ }^{1}$ Estudantes do Bacharelado em Sistemas e Mídias Digitais (UFC). Instituto UFC Virtual, Universidade Federal do Ceará. Campus do Pici - Fortaleza - CE - Brasil.

${ }^{2}$ Doutoranda do Programa de Pós-Graduação em Educação Brasileira - Universidade Federal do Ceará - Faculdade de Educação - Fortaleza - Ceará - Brasil- Bolsista FUNCAP
}

${ }^{3}$ Grupo de Pesquisa e Produção de Ambientes Interativos e Objetos de Aprendizagem PROATIVA. Instituto UFC Virtual, Universidade Federal do Ceará. Av. Humberto Monte, s/n, bloco 901, $1^{\circ}$ andar CEP: 60.455-760 Fortaleza - CE - Brasil.

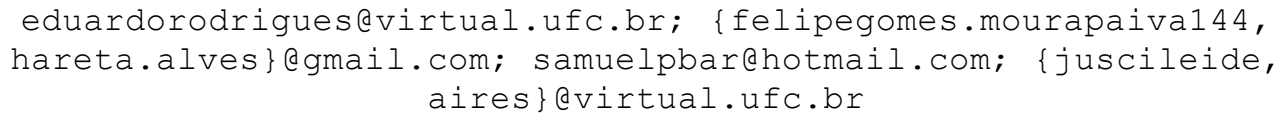

Resumo. Este trabalho descreve o desenvolvimento de um Recurso Educacional Digital (RED) considerando princípios de Design de Interação Humano-Computador (IHC) e de Design de Interfaces Gráficas (DIG), assim como pesquisas empíricas. O RED destina-se ás aulas de Matemática, mas tem potencial intra e interdisciplinares proporcionadas pelos gráficos e produções textuais. Como público-alvo têm-se os estudantes da Educação Básica, com faixa etária entre 11 e 13 anos, ou seja, do $6^{\circ}$ e $7^{\circ}$ ano do Ensino Fundamental. Em estudos futuros pretende-se verificar a eficácia do método de desenvolvimento do RED e implementar o desenvolvimento colaborativo do recurso através de plataformas onlines de desenvolvimento.

\section{Cenário de Uso}

Em todos os dias e a todo o momento somos bombardeados por informações que precisam ser compreendidas, pois disso depende um bom convívio social. Aprender a analisar e interpretar criticamente os dados, como os encontrados nas mais diversas notícias em meios como jornais, revistas e internet, pode permitir uma melhor compreensão da realidade e o desenvolvimento de uma atitude crítica com relação à sociedade. Para isso, é necessário que as pessoas consigam transpor os conhecimentos aprendidos na escola para sua vida diária, desenvolvendo o hábito de questionar criticamente os valores, as grandezas e os dados.

Pesquisas realizadas pelo Indicador Nacional de Alfabetização Funcional (INAF) com a população adulta brasileira de 15 a 64 anos de idade, contatou que apenas $16 \%$ estão no nível pleno, pois, "resolvem problemas que exigem maior planejamento e controle, envolvendo percentuais, [...] interpretar tabelas de dupla entrada, mapas e gráficos" [Inaf, 2011, p. 4]. 


\section{CBIE-LACLO 2015}

Anais dos Workshops do IV Congresso Brasileiro de Informática na Educação (CBIE 2015)

Ainda que os Parâmetros Curriculares Nacionais (PCN) mencionem em alguns de seus objetivos o desenvolvimento da transversalidade, do espírito científico e da formação cidadã dos estudantes, colocar a educação matemática em diálogo com a construção da cidadania pode ser um grande desafio [Brasil, 1997].

Diretrizes para a educação matemática [BRASIL, 1998a, 1998b] defendem seu ensino através do desenvolvimento integrado dos conhecimentos. Assim, constata-se a necessidade de um trabalho mais efetivo com os gráficos, relacionando o Tratamento da Informação, o conhecimento diário e a Matemática, além de outros conhecimentos curriculares como Ciências, Língua Portuguesa, Geografia, História, dentre outros.

Desta forma, entende-se que a escola precisa oportunizar a diversidade de experiências por meio de ações práticas, pois, isso possibilitará que os estudantes compreendam melhor os diferentes conceitos existentes nas disciplinas escolares [Castro, Castro-Filho, 2012].

Com recursos didáticos, a tecnologia tem o potencial de favorecer a representação de informações com mais agilidade; a simulação de diferentes situações; o trabalho com situações reais por meio de contextos investigativos e, portanto, tratar a informação de todo um processo investigativo [Castro, 2012].

Assim, conforme algumas pesquisas [Castro, 2012; Castro, Castro-Filho, 2012], a integração curricular, isto é, a combinação de diferentes linguagens e tecno logias pode favorecer além da apropriação tecnológica, a formação cidadã, embasado em tudo que foi descrito acima está em fase de desenvolvimento o Recurso Educacional Digital (RED) denominado de Esquadrão Graphics: em repórter por um dia.

Esse recurso destina-se, principalmente, para as aulas de Matemática, contudo, devido ao contexto narrativo e as possibilidades intra e interdisciplina res que os gráficos possuem, poderá ser utilizado em aulas de Língua Portuguesa para explorar, por exemplo, o gênero textual reportagem e em outras disciplinas curriculares quando o objetivo for representar informações em forma de gráfico de barras ou linhas, fazendo a devida interpretação de forma textual. Como público-alvo têm-se os estudantes da Educação Básica, com faixa etária entre 11 e 13 anos, ou seja, do $6^{\circ}$ e $7^{\circ}$ ano do Ensino Fundamental.

Na seção seguinte apresentar-se-á o processo de desenvolvimento adotado e as tecnologias utilizadas para a elaboração do referido recurso. Em seguida, serão mostradas telas e melhor detalhado suas funcionalidades. Por fim, estarão dispostas as considerações finais.

\section{Desenvolvimento}

O Esquadrão Graphics, tem como base de desenvolvimento técnico os princípios de Design de Interação Humano-Computador (IHC) e de Design de Interfaces Gráficas (DIG). Da IHC são aproveitadas as características do utilizador e o poder computacional para desenvolver sistemas interativos que sejam funcionais e que atendam as expectativas do usuário [Barbosa e Silva, 2010]. O estudo dos princípios e regras necessárias para a construção da interface do aplicativo baseia-se no DIG.

Os conceitos de IHC são oriundos de estudos da engenharia de software e mostram que as características humanas, isto é, as necessidades do usuário, quando somadas ao poder computacional podem gerar sistemas muito mais fáceis de serem 


\section{CBIE-LACLO 2015}

Anais dos Workshops do IV Congresso Brasileiro de Informática na Educação (CBIE 2015)

utilizados, com maior eficiência e que satisfazem a expectativa do usuário. Logo, o RED desenvolvido possui os seguintes conceitos de IHC: significantes, usabilidade $^{1} \mathrm{e}$ comunicabilidade [Nielsen, 1993; Barbosa e Silva, 2010].

Os conceitos de DIG provêm dos estudos de vários designers a respeito da importância da interface na relação do usuário com o sistema e sobre a forma correta de utilizar a estrutura hierárquica e as indicações durante o processo de desenvolvimento de uma interface gráfica. Desta forma, foram definidos os seguintes princípios no RED: consistência, hierarquia, personalidade, visibilidade, restrições, mapeamento e feedbacks [Norman, 2006; Schlatter e Levinson, 2013].

Desta forma, a escolha dos conceitos definidos, tanto de IHC como de DIG, justifica-se pelo fato de que juntos proporcionam a construção de um recurso que atende as necessidades e expectativas do usuário e que pode ser facilmente utilizado.

A base pedagógica está fundamentada na pesquisa de mestrado de Castro (2012) que apresenta evidências de que a utilização de um RED de gráfico de barras ${ }^{2}$ em conjunto com $b \log ^{3}$ pode proporcionar uma melhor compreensão na resolução de situações-problema, assim como contribuir para o desenvolvimento de atividades investigativas, ligadas ao tratamento da informação [Castro, 2012; Castro, Castro-Filho, 2012].

Para a definição da narrativa do RED Esquadrão Graphics foi realizada uma pesquisa, em uma escola Municipal do município de Fortaleza, com 186 alunos do $6^{\circ} \mathrm{e}$ $7^{\circ}$ anos do Ensino Fundamental (público-alvo do RED), por meio de questionário, com o objetivo de conhecer os hábitos e preferências dos estudantes. Os resultados revelaram a preferência pelo gênero narrativo aventura e de personagens com características heroicas no estilo de HQs (Revista em quadrinhos).

Com a definição dos requisitos técnicos, pedagógicos e da narrativa do RED, iniciou-se seu desenvolvimento em HTML5, CSS3 e Javascript, por ser compatível com a maioria dos atuais navegadores web e, portanto, não necessitar de instalação de plugins ou programas de terceiros, além de poder ser facilmente editado, fator que possibilita o desenvolvimento colaborativo.

A interface foi desenvolvida com base nos princípios definidos na concepção do projeto e procurando sempre ser a mais usual possível. Desta forma, para garantir a usabilidade do recurso, foi desenvolvido um protótipo de baixo nível para teste. Essa avaliação foi realizada com 10 estudantes do $6^{\circ}$ e $7^{\circ}$ anos do Ensino Fundamental, sendo cinco alunos de cada, com a intenção de avaliar o desempenho, a impressão e as opiniões dos usuários. Para isso, optou-se como metodologia o grupo focal, por permitir a discussão entre os participantes e a expressão de opiniões, sem que estas estejam limitadas a uma prévia concepção do pesquisador [Gomes, 2003].

Os resultados motivaram modificações na interface, pois, mostraram-se necessárias para facilitar o uso e melhorar a experiência do usuário, assim com contribuiu para a definição de estilo de personagens.

\footnotetext{
${ }^{1}$ Está relacionada com a facilidade de aprendizado e recordação, eficiência, segurança no uso e satis fação do usuário

http://www.proativa.virtual.ufc.br/manipulatives/manipulativos/grafico_de_barras/nav/frames_asid_323_ g_4_t_5.html

http://1mundodeinformacoes.blogspot.com.br/
} 


\section{CBIE-LACLO 2015}

Anais dos Workshops do IV Congresso Brasileiro de Informática na Educação (CBIE 2015)

O RED Esquadrão Graphics: em repórter por um dia, encontra-se na fase final de desenvolvimento, na qual falta a inserção das opções de ajuda na parte de construção do gráfico, da matéria e na tela inicial, além disso, também será inserida a narrativa animada após a tela inicial, personalização dos personagens de acordo com cada tela e uma tela de resultados após a criação da matéria. A seguir, será apresentada a narrativa, assim como a interface do RED com suas funcionalidades.

\section{Apresentação do recurso}

O cenário inicial apresenta um mundo fictício que é protegido por um grupo de heróis que defendem o planeta de vilões. No RED desenvolvido, a narrativa começa mostrando um vilão misterioso que ataca a sede da revista Graphics, raptando o editor chefe e apagando todos os arquivos da revista. O Esquadrão, formado por três heróis, ao receber um pedido de socorro, vai à sede da revista para investigar. Ao descobrir o ocorrido decidem partir em busca do vilão para resgatar o editor chefe. Contudo, verifica-se um problema: "Quem irá fazer a matéria da revista?" Nesse momento o usuário é convidado a ajudar o Esquadrão Graphics, pois, enquanto os heróis vão em busca do vilão, o aluno irá fazer a matéria e ajudar a salvar a ed ição da revista.

A partir da narrativa que consta no início do RED, existe a necessidade da produção de uma notícia que precisará ser veiculada na revista, o usuário poderá escolher um herói, de um total de três, para auxiliá- lo na construção de um gráfico e da notícia, enquanto os demais vão em busca de salvar o repórter, que segundo a narrativa, foi seques trado por um vilão (ver figura 01).

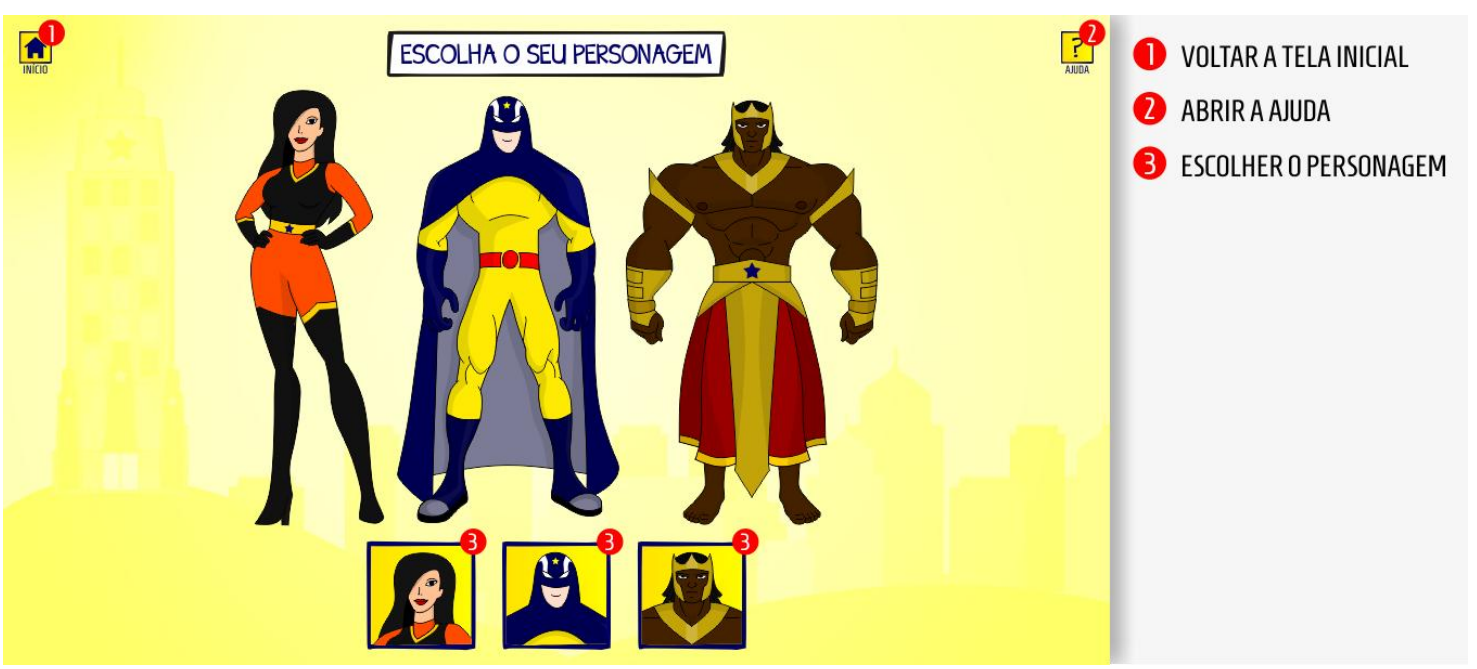

Figura 01 - Tela com interface de escolha do personagem com legenda explicativa

Vale ressaltar que todos os três personagens possuem além das características físicas diferentes, mas, também, qualidades heroicas como força, inteligência, rapidez. Após a escolha do personagem, este interagirá com o usuário até a conclusão da atividade (ver figura 02). 


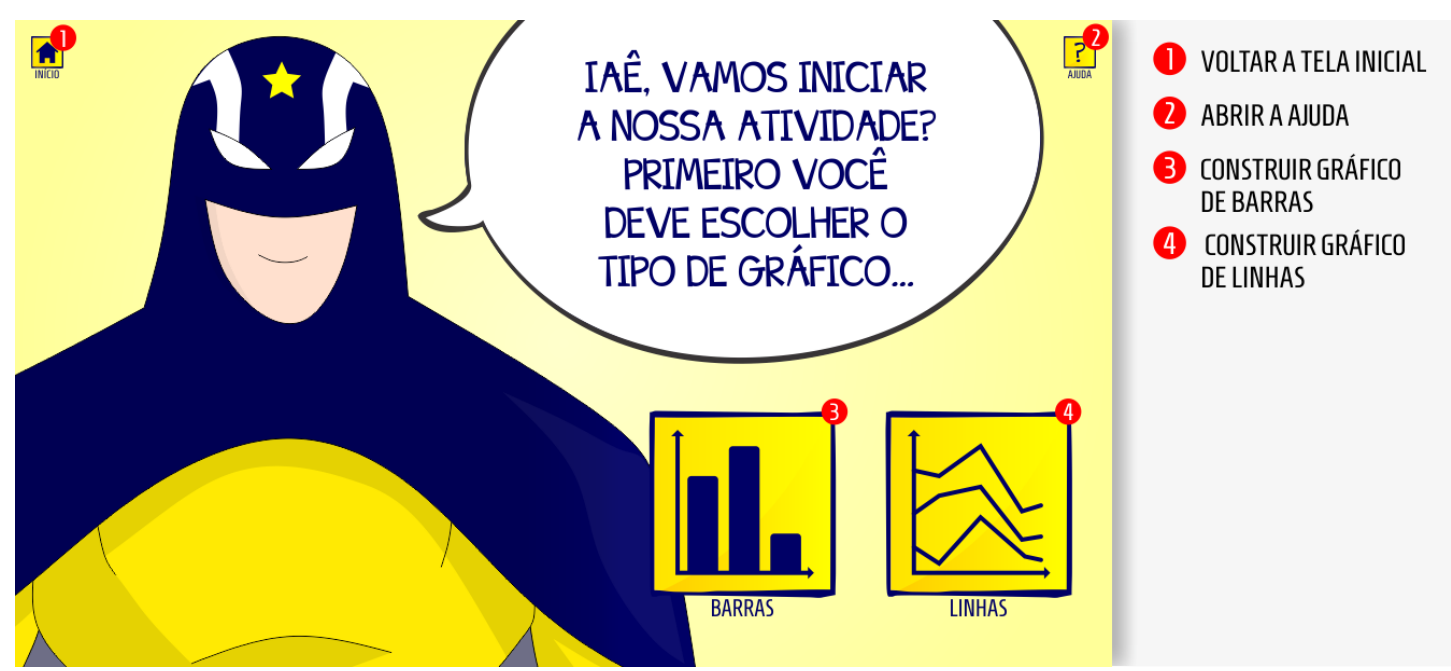

Figura 02 - Tela com interface de escolha do tipo de gráfico com legenda explicativa

A figura 02 mostra que é possível escolher entre dois tipos de gráficos: de barras e de linhas. Com a escolha do gráfico, será solicitada a configuração da malha, ou seja, a delimitação do espaçamento desejado que servirá de base para a construção do gráfico. A mudança desse espaçamento poderá ser feita a qualquer momento, desde que se acesse o botão malha, como pode ser visto na figura 03 , na legenda 8 .

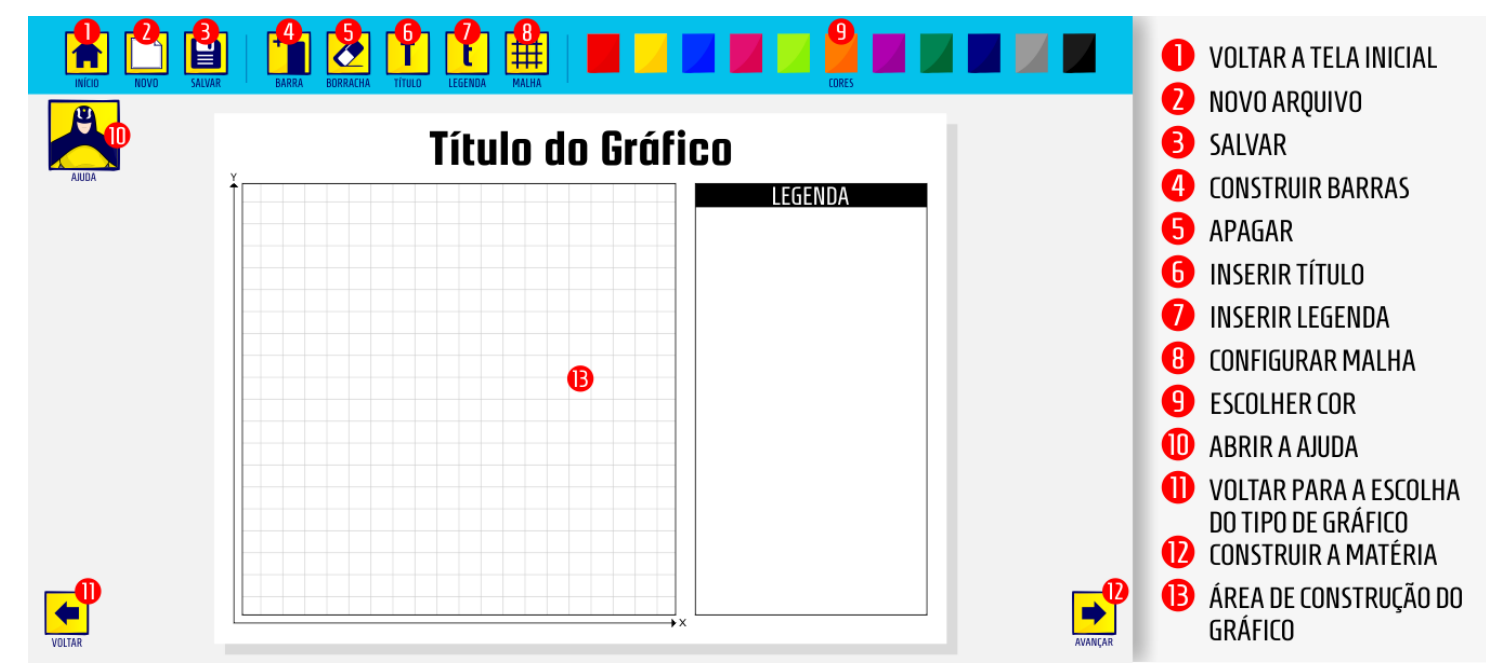

Figura 03 - Tela com interface de construção do gráfico com legenda explicativa

Outras funcionalidades estão disponíveis na interface de construção de gráficos: criação de novo arquivo; possibilidade de salvar; a opção de construir as barras ou linhas, dependendo do gráfico escolhido; poder apagar o que foi feito; inserir título e legenda, escolha das cores de cada barra ou linha (figura 03). Após a construção do gráfico, o usuário deverá avançar para a produção textual da matéria da revista (ver figura 04). 


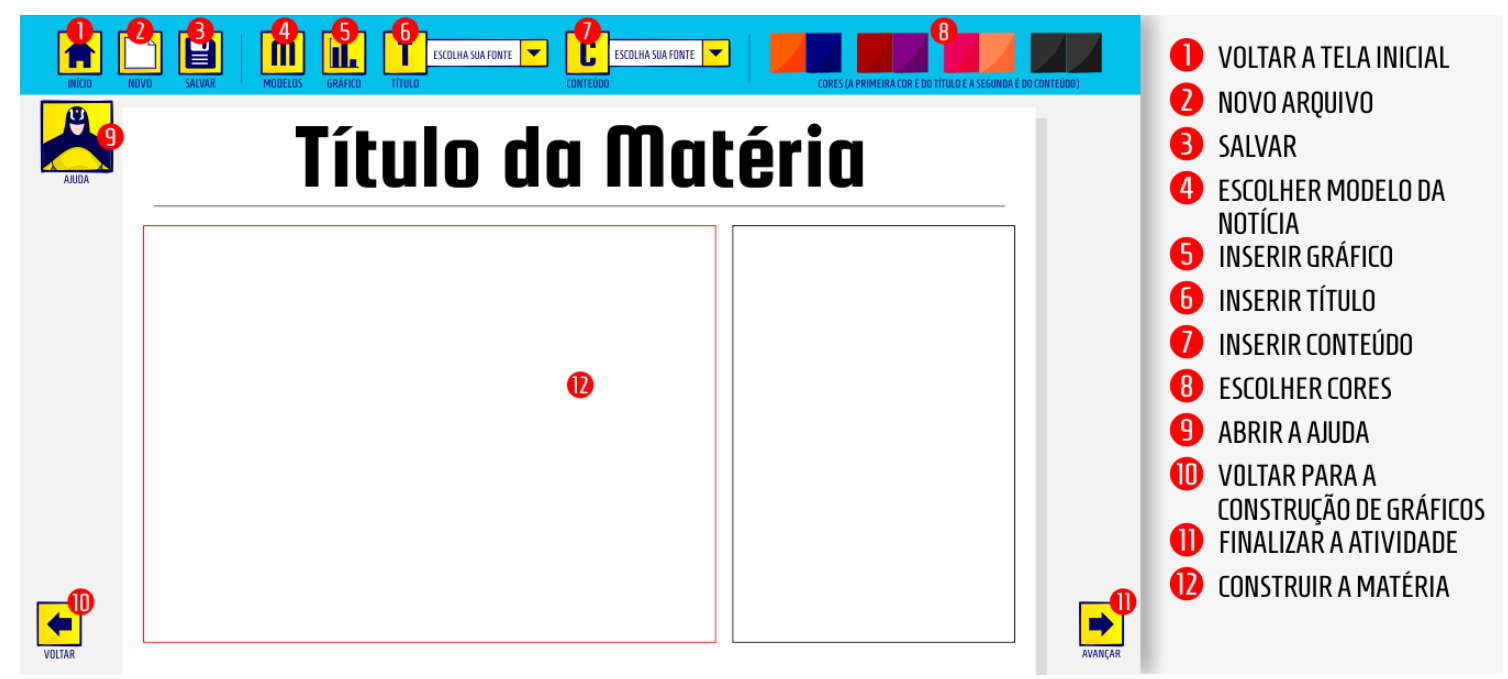

Figura 04 - Tela com a interface de criação da notícia com legenda explicativa

Nessa interface o usuário passa a ter novas opções, como a escolha de modelos (layouts) da notícia; estilo de letras e combinação de cores para título e corpo do texto. Com a finalização da matéria o estudante poderá salvá-la em formato de imagem com extensão .jpg.

A partir das telas apresentadas, pode-se verificar que as produções criadas pelos alunos a partir do RED Esquadrão Graphics: em repórter por um dia, possuem características interdisciplinares, atendendo recomendação dos PCN de que o estudo de gráficos não devem limitar-se a leitura e interpretação, mas de possibilitar que os estudantes sejam "capazes de descrever e interpretar sua realidade, usando conhecimentos matemáticos" [Brasil, 1997, p. 69]. A seguir serão feitas as considerações finais.

\section{Considerações finais}

O RED Esquadrão Graphics: em repórter por um dia é um recurso com características interdisciplinares por permitir a ligação do Tratamento da Informação, bloco pertencente à Matemática, de acordo com os PCN, com a Língua Portuguesa, por necessitar a compreensão das características do gênero textual notícia [Brasil, 1997; 1998a; 1998b].

Espera-se que esse RED possibilite o desenvolvimento do espírito científico e da formação cidadã dos estudantes, colocando a educação matemática em diálogo com a construção da cidadania por meio de atividades intra e interdisciplinares proporcionadas por meio dos gráficos e das produções textuais.

O seu desenvolvimento tem sido definido buscando um design atrativo e compreensível para a faixa etária definida, assim como com requisitos técnicos que não sejam obstáculos de uso nas diferentes escolas brasileiras, ou seja, não requisitando plugins e possibilitando funcionamento em qualquer sistema operacional.

Contudo, ao final de seu desenvolvimento, pretende-se fazer validação do RED junto ao público-alvo, assim como, a preparação de um guia para que os professores possam compreender possibilidades didáticas do RED.

Como estudos futuros pretende-se verificar a eficácia do método de desenvolvimento do RED, do qual foi colaborativo com o usuário, comparando com o 


\section{CBIE-LACLO 2015}

Anais dos Workshops do IV Congresso Brasileiro de Informática na Educação (CBIE 2015)

desenvolvimento de outros RED. Além disso, considerando as possibilidades que os estudantes possuem de produção, espera-se implementar o desenvolvimento colaborativo do recurso através de plataformas onlines de desenvolvimento.

\section{Referências}

Barbosa, S. D. J.; Silva, B. S. Interação humano-computador. Rio de Janeiro: Elsevier, 2010.

Brasil, MEC/SEF. Parâmetros curriculares nacionais: Matemática. Brasília: MEC/ Secretaria de Educação Fundamental, 1997.

Brasil, MEC/SEF. Parâmetros curriculares nacionais: terceiro e quarto ciclos do ensino fundamental: Introdução aos PCN. Brasília: MEC/ Secretaria de Educação Fundamental, 1998a.

Brasil, MEC/SEF.: Matemática. Brasília: MEC/Secretaria de Educação Fundamental, 1998b.

Castro, J. B. O uso de objetos de aprendizagem para a construção e compreensão de gráficos estatísticos. Fortaleza: UFC, 2012. 215 p. Dissertação (Mestrado) Programa de Pós-Graduação em Educação Brasileira, UFC, Fortaleza, 2012.

Castro, J. B.; Castro-Filho, J. A. Projeto Um Mundo de Informações: Integração de Tecnologias Digitais ao Currículo Escolar. I Congresso Brasileiro de Informática na Educação. Rio de Janeiro: Worshop sobre formação e experiências educacionais no programa Um Computador por Aluno - I CBIE. 2012. p. 1-10.

Inaf, Brasil 2011: principais resultados. Instituto Paulo Montenegro em parceria com a ONG Ação Educativa. 2011.

Gomes, A. A. Usos e possibilidades do grupo focal e outras alternativas metodológicas. V. 2. n. 1 - julho de 2003.

Norman, D. A. O design do dia-a-dia. Rio de Janeiro: Rocco, 2006.

Schlatter, T. ; Levinson, D. Visual Usability: Principles and Practices for Designing Digital Applications, Massachusetts :Morgan Kaufmann Publishers, 2013. 